\title{
Electrochemical Approach to the Study of the Antioxidant Capacity of Vaccinium Meridionale Swart at Different Ripening Stages
}

\author{
Elisa García-Carvajal, Lucas Blandón-Naranjo, Víctor Villa-Montoya, \\ Mario V. Vázquez * and Carlos Peláez-Jaramillo \\ Interdisciplinary Group of Molecular Studies -GIEM. Chemistry Institute, \\ University of Antioquia. Calle 67 No. 53 - 108, Medellín, Colombia
}

Received June 28, 2017; accepted October 25, 2017

\begin{abstract}
The study of tropical fruits' nutraceutical properties has been of great interest in the food research area. There are several parameters traditionally used to make fruits quality control, such as organoleptic analysis and physical and chemical assays. This work proposes the use of a simple, fast and low cost electrochemical technique for the characterization of fruit extracts in function of their ripening state, using as biological model a tropical fruit commonly named as Mortiño (Vaccinium meridionale swart). Cyclic voltammetry was selected as an electrochemical technique, due to the possibility of extracting kinetic and thermodynamic information from the results. A good correlation between the fruit extract's physical-chemical properties and electrochemical parameters, such as peak intensity, charge and oxidation peak potential, was obtained.
\end{abstract}

Keywords: antioxidant capacity, electrochemical methods, cyclic voltammetry, Vaccinium meridionale swart, mortiño and ripening states.

\section{Introduction}

Vaccinium genre has received great attention in last years, due to its nutraceutical properties related to antioxidant capacities, which are reported to contribute for the protection of the nervous system [1], reversing the decline in neural and cognitive functioning [2], reducing the damages of cellular components, and the risk of chronic diseases [3], preventing cardiovascular disease [4-5] and degenerative diseases such as Alzheimer's and Parkinson's [6], and controlling diabetes and digestive problems [7].

Additionally, it has been reported to present antioxidant capacities, and cytoprotective effects against oxidative damage in various models in vitro [8].

Most species of Vaccinium are originated from USA and Europe, but some of them, such as Vaccinium meridionale, are reported to grow at 1800 to 3500

\footnotetext{
* Corresponding author. E-mail address: mario.vazquez@udea.edu.co
} 
meters above sea level (masl) $(\approx$ altitude) in tropical countries such as Jamaica, Venezuela, Colombia and Peru [7].

In Colombia, V. meridionale swart is known as "Mortiño" or "Agraz", and has gained commercial positioning among consumers as food and source of functional constituents [6].

So far, there are not enough studies about its physical-chemical properties. The fruit became widely known to herbalists in the 16th century, when it was used for treating bladder stones, biliary disorders, scurvy, coughs and lung tuberculosis [8]. V. meridionale swartz belongs to the Ericaceae family. This is a small wild shrub, usually 1-4 m tall; it grows between 2200 and 3400 altitude (masl). Unripe fruits of mortiño are spherical, with a diameter between 5 and $10 \mathrm{~mm}$. They acquire a greenish color, than reddish, and finally purple-dark, when they are in their highest ripening stage. In this state, the fruit pulp is edible, and has a sweet taste with a variable acidity.

The antioxidant capacity of European and North American bilberry ( $V$. myrtillus) has been extensively investigated [8], and is related with the presence in the fruit of different metabolites as polyphenolic compounds, such as flavonoids, anthocyanins and tannins [9]. These metabolites are expressed in different stages of ripening, soil and climate conditions, and fertilization programs, among others [10].

Traditionally, the antioxidant capacity is measured using chemical assays such as DPPH, ABTS and FRAP, which give information about the ability of redox molecules in foods and biological systems to scavenge synthetic radicals [11-12]. An alternative to these methods consists of electrochemical techniques, which bring information about the electro activity of several molecules. A molecule that has high antioxidant capacities is a good reductive agent, which is related to the oxidation potential measured by voltammetric techniques, such as linear voltammetry (LV), cyclic voltammetry $(\mathrm{CV})$, or square wave voltammetry (SWV) [13-17].

Cyclic voltammetry is an useful tool for the determination of the total antioxidant capacities of wines [18,19], fruit tea infusions [13] and juices [20], among others.

Due to the limited information reported about mortiño maturation process, and its relation with the electroactive species, the aim of the present work was to investigate the electrochemical behavior of methanolic extracts from different ripening states of $V$. meridionale swarts on a glassy carbon electrode using cyclic voltammetry.

In order to confirm the effectiveness of these technique for the characterization of $V$. meridionale in several ripening stages, physical-chemical characterization assays, such as Folin-Ciocalteau method to assess total phenolic content, DPPH to determinate the antioxidant capacity, $\mathrm{pH}$ differential method to obtain anthocyanin quantification, and bromatological assays on moisture, ashes, total fatty and total nitrogen determination were carried out. 


\section{Methodology}

Sample collection

V. meridionale samples were collected from wild bushes in the village of El Chuzcal, El Retiro - Antioquia (altitude: 2341 masl, N: 6 04. 264", E: 75 26. 977'). Fruit samples harvest was made in December 2016. Six ripening stages were selected according to the color, and labeled as S1 to S6, according to CIELAB color space, and the $\mathrm{L}$, $\mathrm{a}$, and $\mathrm{b}$ parameters. The selected nomenclature corresponds to the maturation process (immature: S1 - completely mature: S6). For every physicochemical analysis, a representative sample was taken, in order to be used in the corresponding procedure.

\section{Sample preparation}

The ground powder of each stage $(10 \mathrm{~g})$ was mixed with $30 \mathrm{~mL}$ of acidic methanol $(1 \% \mathrm{HCl})$ in a $100 \mathrm{~mL}$ beaker. The beaker and its contents were immersed into an ultrasound bath during $10 \mathrm{~min}$. After being extracted, the mixture was filtered. This process was repeated two more times. The solvent was removed with a rotary vacuum evaporator at $50{ }^{\circ} \mathrm{C}$.

After picking the appropriate maturity stages, samples of each six stages were freeze-dried, milled, and stored in dark recipients at $2{ }^{\circ} \mathrm{C}$. Freeze-dried samples were grounded for subsequent extraction and physical-chemical analysis.

\section{Electrochemical analysis}

Voltammetric analysis was performed in a Metrohm Autolab Potentiostat PGSTAT 101 integrated with NOVA 1.1 ® software. A typical three electrode configuration, consisting of a Glassy Carbon (GCE) as working electrode, $\mathrm{Ag} / \mathrm{AgCl}$ as reference, and $\mathrm{Pt}$ wire as counter electrode, was used. GCE was polished in a $0.3 \mu \mathrm{m}$ and $0.05 \mu \mathrm{m}$ alumina powder and, then, cycled for 10 times in a $0.01 \mathrm{~mol} \mathrm{~L}^{-1}$ phosphate buffer solution (PBS, prepared at $\mathrm{pH} 7$ from $\mathrm{NaH}_{2} \mathrm{PO}_{4}, \mathrm{Na}_{2} \mathrm{HPO}_{4}$ and $\mathrm{KCl} 0.1 \mathrm{~mol} \mathrm{~L}^{-1}$ as supporting electrolyte), from $-0.1 \mathrm{~V}$ to $1 \mathrm{~V}$, previously to each measurement. Samples were prepared by diluting 2.0 $\mathrm{mL}$ of the PBS extract. A cyclic voltammetry analysis was carried from $-0.1 \mathrm{~V}$ to $1.0 \mathrm{mV}$, at a scan rate of $100 \mathrm{mV} / \mathrm{s}$. All analyses mentioned in the methodology were performed in triplicate.

\section{Physical-chemical characterization}

The average berry fresh weight was determined according to the weight of 30 berries. Volume was determined using the model of an ellipsoid, $V=\frac{4}{3} \pi r_{1} r_{2} r_{3}$, and the color analysis was performed on the freeze-dried fruit using the official ASTM method D2244 - 14 (results not shown). Extraction of metabolites was made as follows: a mass $(2.000 \mathrm{~g})$ of the freeze-dried fruit was extracted with methanol containing $1.0 \%$ hydrochloric acid. Three successive extractions were performed, each one with $30 \mathrm{~mL}$ of acidified methanol during 10 min under sonication, according to Chiou et al. [21]. Extracts were filtered in a $0.1 \mu \mathrm{m}$ pore size cellulose filter, and all visible pigments were removed from the solution slurry. Each extract was concentrated at $45^{\circ} \mathrm{C}$, at low pressure, and stored in amber vessels at $-5^{\circ} \mathrm{C}$. 
Total phenolic content was measured using Folin-Ciocalteu method (FC) [22]. $1.5 \mathrm{~mL}$ of FC reagent (dilutes 1:10 in water) was added to $0.5 \mathrm{~mL}$ of the extract appropriately diluted with methanol, to ensure that the absorbance was in the range of $0.7-2.4$. The mixture was allowed to react $5 \mathrm{~min}$, and then, $1.5 \mathrm{~mL}$ of $7.5 \% \mathrm{Na}_{2} \mathrm{CO}_{3}$ was added. The samples were incubated at room temperature, in a dark place, for $60 \mathrm{~min}$; the absorbance was measured at $760 \mathrm{~nm}$. The results are expressed as mg gallic acid equivalents/100 g sample (dry fruit (DF)). Each assay was carried out in triplicate.

The antioxidant capacity was determined using DPPH as radical. $0.5 \mathrm{~mL}$ of a 0.5 $\mathrm{mM}$ methanolic solution of DPPH was added to $1.5 \mathrm{~mL}$ of each extract (appropriately diluted with methanol to obtain an absorbance in the range of 0.8 to 1.5). The absorbance of the reaction mixture was measured at $515 \mathrm{~nm}$, after 60 min of reaction. In order to evaluate the antioxidant capacity, the absorbance sample was interpolated onto Trolox $®$ calibration curve $\left(\mathrm{R}^{2}=0.9946\right)$, and expressed in mg Trolox $® / 100 \mathrm{~g}$ DW. Each assay was carried out in triplicate. For total anthocyanin determination, the differential $\mathrm{pH}$ method, according to AOAC Official Method 2005.02, was employed. Results are reported as $\mathrm{mg}$ of cyanidin-3-glycoside (C-3-G) $\mathrm{g}^{-1}$ of dry fruit.

HPLC/MS analysis for metabolite quantification was carried out using a HPLC Agilent® 1200 series with a Zorbax Eclipse XDB-C18 $4.6 \mathrm{~mm}$ x $100 \mathrm{~mm}$ column and a 3.5 microns column, and coupled with a VL MSD 6410 quadrupole Mass Spectrometer detector. The ions to be monitored for the $(+)-$ catechin and (-) - epicatechin were $289(\mathrm{~m} / \mathrm{z})$ and $245(\mathrm{~m} / \mathrm{z})$, respectively, and the voltage fragmentation was $150 \mathrm{~V}$. For gallic acid, $169(\mathrm{~m} / \mathrm{z})$ and $125(\mathrm{~m} / \mathrm{z})$ ions at $130 \mathrm{~V}$ were monitored, and for ellagic acid, the monitored ion was $301(\mathrm{~m} / \mathrm{z})$ at $150 \mathrm{~V}$.

\section{Statistical evaluation}

Differences between means were assessed by one way analysis of variance (ANOVA), followed by least significant differences (LSD), version 15.1.02. $\mathrm{P}<$ 0.05 , and they were considered significant.

Statistical analyses of electrochemical parameters and DPPH assay were made using multiple variable correlations. All the studies were carried out using STATGRAPHICS® Centurion XV.

\section{Results and analysis \\ Electrochemical analysis}

Voltammograms of different ripening states are show in Fig. 1. S1, S2 and S3 present two oxidation peaks: one in the range of $0.45 \mathrm{~V}-0.54 \mathrm{~V}$, and the other in the range of $0.75 \mathrm{~V}-0.82 \mathrm{~V}$. For these ripening states, it was observed a reduction peak around $0.35 \mathrm{~V}$. On the other hand, S4, S5 and S6 showed one oxidation peak around $0.25 \mathrm{~V}$, with a corresponding reduction peak at approx. $0.15 \mathrm{~V}$. The oxidation peak potential for the first ripening stages decreased in function of fruit maturity. For S4, the peak completely disappears, but it appears a new peak at lower anodic potential, which remains for the next two ripening 
stages: S5 and S6. This behavior can be related to the disappearance of electroactive species, and the formation of new ones.

The second peak in the voltammogram for $S 1, S 2$ and $S 3$ could be related to the electrochemical behavior molecules with a cathecol group in their structure (quercetin, catechin, and gallic acid). For these ones, it has been reported a ECE mechanism, which starts an electrochemical oxidation (first anodic peak), due to the cathecol group oxidation; then, chemical stabilization is carried out forming an intermediate species, which reacts over the electrode, and is responsible for the second oxidation peak [23-24]. However, because the sample is a product of natural extraction, the second peak could be related to the presence of other single phenol-type electroactive species, which usually exhibit high oxidation overpotentials. As the origin of the second peak could be misled, and the experimental data do not offer overwhelming conclusions for posterior analysis, we only consider the first oxidation extracts peak.

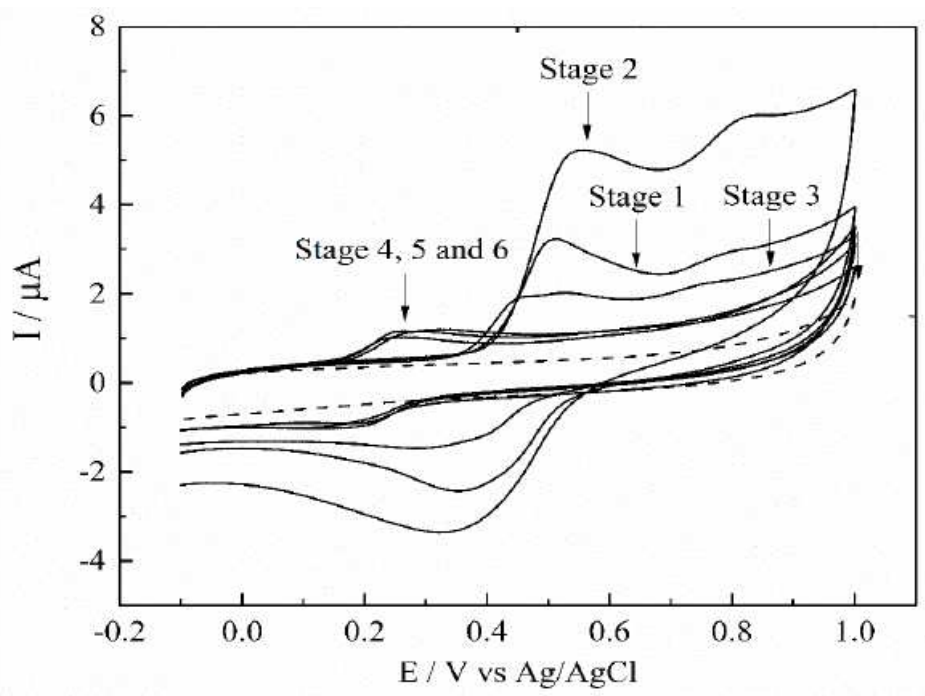

Figure 1. Cyclic voltammograms for extracts at different ripening stages diluted in $\mathrm{pH}$ 7.0 phosphate buffer; $v: 100 \mathrm{mV} \mathrm{s}^{-1}$. The dotted line corresponds to the blank.

From the point of view of the peaks current intensity, proportionality between the oxidation current peak values and the metabolite concentration is expected, but due to every peak, it is probably a sum of different electroactive metabolites present in every ripening state extracts. The charge (area under the curve) for every voltammetry, for the oxidation scan from $0 \mathrm{~V}$ to $0.8 \mathrm{~V}\left(\mathrm{Q}_{800}\right)$, which can be related with the total contribution of electroactive species [25], was calculated. Also, $E_{1 / 2}$ and the difference between this and $E_{p}$ were extracted from cyclic voltammetries. The results are summarized in Table 1.

From the table, it is possible to note that the first oxidation peak is less anodic, as the fruit matures. S1 presents a lower oxidation potential than that of S2, which corresponds to the other variables showed in the table. This phenomenon will be later discussed in this work. The diminution in $\mathrm{E}_{\mathrm{p}, \mathrm{a}}$ implies a better extract reducing capacity. The difference between $\mathrm{E}_{\mathrm{p}, \mathrm{a}}$ and $\mathrm{E}_{\mathrm{p} / 2}$ can also diagnose a reversible electron transfer. A short value between them implies an irreversible electron transfer kinetics. As shown in Table 1, this difference decreases with the 
ripening state, what is in accordance with the voltammograms; these display a peak that, for S4, S5, and S6, suffers no reductions, but that undergoes a decrease in the first three ripening stages.

Table 1. Electrochemical parameters for the anodic peak determined from the cyclic voltammograms of ripening stages, measured at $100 \mathrm{mV} \mathrm{s}^{-1}$ in a $\mathrm{pH} 7.0$ phosphate buffer.

\begin{tabular}{clcccc}
\hline Stage & \multicolumn{1}{c}{$\begin{array}{c}\mathbf{E}_{\mathbf{p}, \mathbf{a}} \\
(\mathbf{V})\end{array}$} & $\begin{array}{c}\mathbf{E}_{\mathrm{p} / \mathbf{2}} \\
(\mathbf{V})\end{array}$ & $\begin{array}{c}\mathbf{E}_{\mathbf{p}, \mathrm{a}}-\mathbf{E}_{\mathrm{p} / \mathbf{2}} \\
(\mathbf{V})\end{array}$ & $\begin{array}{c}\mathbf{I}_{\mathbf{p}, \mathbf{a}} \\
(\boldsymbol{\mu} \mathbf{A})\end{array}$ & $\begin{array}{c}\mathbf{Q}_{800} \\
(\boldsymbol{\mu} \mathbf{C})\end{array}$ \\
\hline $\mathbf{1}$ & $0.52 \pm 0.01(0.79)$ & $0.4 \pm 0.01$ & 0.12 & $2.8 \pm 0.3$ & $1.3 \pm 0.1$ \\
$\mathbf{2}$ & $0.54 \pm 0.01(0.82)$ & $0.47 \pm 0.01$ & 0.07 & $4.4 \pm 0.3$ & $1.8 \pm 0.1$ \\
$\mathbf{3}$ & $0.45 \pm 0.01(0.75)$ & $0.38 \pm 0.01$ & 0.07 & $1.8 \pm 0.2$ & $1.1 \pm 0.1$ \\
$\mathbf{4}$ & $0.27 \pm 0.02$ & $0.19 \pm 0.03$ & 0.08 & $1.10 \pm 0.09$ & $0.83 \pm 0.04$ \\
$\mathbf{5}$ & $0.25 \pm 0.004$ & $0.18 \pm 0.01$ & 0.07 & $0.98 \pm 0.06$ & $0.82 \pm 0.02$ \\
$\mathbf{6}$ & $0.24 \pm 0.00$ & $0.17 \pm 0.01$ & 0.07 & $0.6 \pm 0.1$ & $0.7 \pm 0.1$ \\
\hline
\end{tabular}

For a better understanding of this behavior, a voltammetric study, with some standards that are usually reported as metabolites present in Vaccinium genre, was made. Additionally, Trolox ${ }^{\circledR}$, which is a molecule often used as standard for antioxidant capacity determination, was measured, although is not a metabolite. The results are summarized in Table 2. According to the oxidation potential reported in Table 2, the reductive power (lower anodic potential peak) is in order of increasing size, as follows: quercetin, trolox, catechin, gallic acid, ascorbic, genistein and flavanone.

Table 2. Cyclic voltammetry parameters for $5.0 \mathrm{mM}$ phenolic standards in a $\mathrm{pH} 7.0$ phosphate buffer.

\begin{tabular}{|c|c|c|c|c|c|}
\hline $\begin{array}{c}\text { Molecule } \\
\text { (kind of molecule) }\end{array}$ & $\begin{array}{l}E_{p, a} \\
\text { (V) }\end{array}$ & $\begin{array}{l}E_{p / 2} \\
\text { (V) }\end{array}$ & $\begin{array}{c}E_{p, a}-E_{p / 2} \\
(V)\end{array}$ & $\begin{array}{l}I_{p, a} \\
(\mu A)\end{array}$ & $\begin{array}{l}Q_{800} \\
(\mu A)\end{array}$ \\
\hline Quercetin (flavonol) & $0.09(0.88)$ & 0.04 & $0.05(0.13)$ & 3.56 & 3.32 \\
\hline Trolox $®$ (standard) & 0.17 & 0.09 & 0.08 & 4.66 & 2.08 \\
\hline Catechin (flavonol) & $0.25(0.63)$ & $0.16(0.55)$ & $0.09(0.08)$ & 5.9574 & 5.29 \\
\hline Gallic acid (simple phenol) & $0.26(0.61)$ & $0.16(0.55)$ & $0.10(0.06)$ & $4.94(0,51)$ & 4.33 \\
\hline Ascorbic acid (vitamin) & 0.27 & 0.11 & 0.16 & 4.01 & 2.00 \\
\hline Genistein (isoflavone) & 0.59 & 0.49 & 0.1 & 0.5468 & 0.31 \\
\hline Flavanone & ---- & ---- & ---- & ---- & ---- \\
\hline
\end{tabular}

As reported in literature [23,24,26], quercetin and catechin present two oxidation peaks. Gallic acid, as well, presents this two signals, due to the hydroxyl groups in its structure [19].

Gallic acid, quercetin, catechin and trolox ${ }^{\circledR}$ have phenolic substituents over the aromatic group, which can be electrochemically oxidized to quinones. This reaction mechanism was proposed by Donald T. Sawyer et al. [27].

The difference in oxidation potentials depends on the number and position of the hydroxyl groups. Flavanones, for example, can exhibit structures with ortho phenol groups, which are more easily oxidized and, in this sense, reduce the oxidation potential [28]. Flavanone does not have hydroxyl groups as substituents, therefore, does not present an electrochemical response. 
For ascorbic acid, the oxidation peak is due to the double bond oxidation, forming an electroinactive product: 2,3- diketogulonic acid; this compound is easily adsorbable onto the electrode surface, which can result in electrode passivation [29].

The only reversible reaction for the evaluated standards in this work corresponds to Trolox, which presents a reduction peak at $0.1 \mathrm{~V}$. The difference between the oxidation and reduction peaks is $70 \mathrm{mV}$, corresponding to a quasi-reversible reaction.

According to the results obtained for the standards, genistein has an oxidation potential over $0.5 \mathrm{~V}$; nevertheless, this compound exhibits only one oxidation peak, while the extracts show two peaks. This may indicate that genistein could be present in the extract, despite not being the only electroactive metabolite. On the other hand, for S4, S5 and S6, the oxidation potentials coincide with catechin, gallic acid and ascorbic acid compounds.

\section{Physico-chemical analysis}

In order to obtain a better interpretation of electrochemical data, several studies were performed for characterizing this kind of samples: total polyphenols by Folin-Ciocalteau method, antioxidant capacity by DPPH assay, and metabolite quantification by HPLC-MS. The results obtained for total polyphenolic content and TEAC are shown in Fig. 2.

It was observed a reduction of $57.4 \%$ between $\mathrm{S} 2$ and S6. The reduction of phenolic compounds is similar to that reported in the literature [30], where the difference among the maximum and the minimum value was $71.4 \%$.

On the other hand, a related work concerning V. corymbosum [10] showed a phenolic concentration reduction from $70 \mathrm{mg}$ gallic acid/100 $\mathrm{g}$ dried weight to 30 $\mathrm{mg}$ gallic acid/100 g DF, during fruit ripening and at selected harvest dates [3132]. The reduction in the total content of polyphenol could be due to the fact that polyphenols such as flavandiols, leucoanthocyanidins, flavanones and cinnamic acids act as biosynthetic precursors of anthocyanins.

Also, HPLC-MS analyses of three polyphenols reported for Vaccinium genre, gallic acid, catechin and epicatechin, were made (Table 3). Gallic acid presents a very low concentration compared to the other two studied substances: zero for the two first ripening stages. In turn, it shows an augment for S3, S4, S5 and S6, as this molecule is a precursor of other kind of molecules, such as flavonoids or anthocyanins.

On the other hand, catechin and epicatechin decrease with time, which is the same behavior for total phenolic quantification made by the FC method. Also, the sum of the concentration for the three metabolites, described at the end of the table, shows a decrease trend; but for S2, the value increases, which agrees with the total polyphenolic content measurement. This reduction in polyphenolic content coincides with the increase in antioxidant capacity and total anthocyanin content, as it can be seen in Fig. 2. Catechins and anthocyanins are synthesized through the flavonoid pathway. This pathway begins with the phenylalanine amino acid. For the action of different enzymes, for example, chalcone synthase 
(CHS), chalcone isomerase (CHI) and dihydroflavonol 4-reductase (DFR), this amino acid is converted in leucoanthocyanidin, a branch point in the pathway.

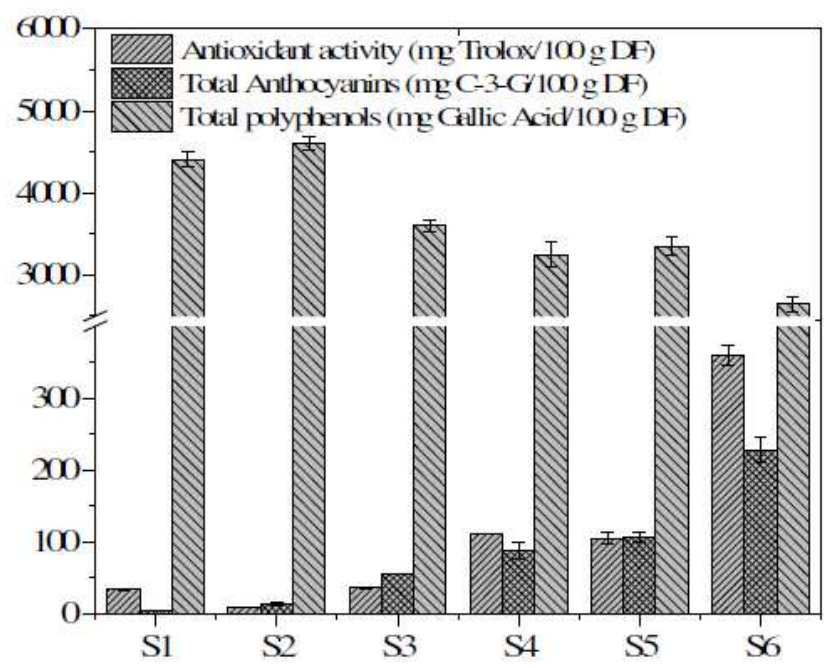

Figure 2. Antioxidant activity (mg Trolox/100 g DF) (white), total anthocyanins (mg C3-G/100 g DF) (grey) and total phenolic content (mg gallic acid/100 g DF) (black) measured for every ripening stage of Vaccinium meridionale $s$.

On one branch, leucoanthocyanidin 4- reductase (LAR) catalyzes leucoanthocyanidin to produce catechin, and partial leucoanthocyanidin is converted into epicatechin by the sequential action of anthocyanidin synthase (ANS) and anthocyanidin reductase (ANR). In the other branch, ANS catalyzes the formation of anthocyanidin, and the latter is converted into anthocyanins, by the sequential action of UDP-glucose flavonoid 3-O-glucosyl transferase (UFGT). Catechins and anthocyanins come from the same precursor; therefore, the increase in anthocyanins concentration, due to ripening effects, directly affects catechins biosynthesis, which is reflected in a decrease in concentration of the latter [32-33].

Table 3. Content of total phenolic compounds, during Vaccinium meridionale s. ripening, measured by HPLC-MS.

\begin{tabular}{|c|c|c|c|c|c|c|c|c|c|c|c|}
\hline $\begin{array}{l}\text { Rippening } \\
\text { stage }\end{array}$ & & S1 & & $\mathbf{S 2}$ & & $\mathbf{S 3}$ & & S4 & & S5 & S6 \\
\hline $\begin{array}{l}\text { Gallic acid } \\
(\mathrm{ppm})\end{array}$ & 0.0 & \pm 0.0 & 0.0 & \pm 0.0 & 1.3 & \pm 0.1 & 1.7 & \pm 0.1 & 0.9 & \pm 0.1 & $3.3 \quad \pm 0.2$ \\
\hline $\begin{array}{l}\text { Catechin } \\
\text { (ppm) }\end{array}$ & 40.9 & \pm 0.2 & 30.4 & \pm 4.3 & 29.0 & \pm 1.5 & 13.5 & \pm 0.7 & 12.7 & \pm 1.0 & $11.6 \pm 0.9$ \\
\hline $\begin{array}{l}\text { Epicatechin } \\
(\mathrm{ppm})\end{array}$ & 428.1 & $1 \pm 10.8$ & 524.4 & $4 \pm 22.5$ & 349.8 & \pm 30.6 & 230.9 & $9 \pm 21.4$ & 174.9 & $9 \pm 15.2$ & $162.4 \pm 10.6$ \\
\hline TOTAL & 479.3 & $3 \pm 11.0$ & 575.9 & $9 \pm 25.8$ & 401.0 & \pm 31.2 & 272.7 & $7 \pm 23.4$ & 218.2 & $2 \pm 16.9$ & $231.3 \pm 12.9$ \\
\hline
\end{tabular}

From the point of view of antioxidant capacities, simple phenol compounds, such as gallic acid, usually exhibit a very high antiradical activity, due to the position of hydroxyl groups, which can stabilize the aryloxyl radical formed after the reaction with radical molecules, namely DPPH [34]. The fact that gallic acid and 
also anthocyanins have an increment in the maturation process can explain the augment in antioxidant capacity, in spite of the reduction in the total polyphenolic content. Also, the important increase in anthocyanin content (Fig. 2) can be responsible for the increase in antioxidant capacity, considering that this kind of molecules has the possibility of being substituent for hydroxyl groups in different positions, which include ortho-phenols that, as previously discussed in section 3.1, can be more easily oxidized than other kind of phenols.

\section{Correlation between electrochemical and physico-chemical studies}

Due to their low redox potentials $\left(0.2 \mathrm{~V}<\mathrm{E}^{\mathrm{o}}<0.8 \mathrm{~V}\right)$, flavonoids and anthocyanins are thermodynamically able to reduce most oxidizing free radicals that are relevant to biological systems, such as superoxide, peroxyl, alkoxyl, and hydroxyl radicals [35]. This kind of molecules is highly electroactive and, from an electrochemical perspective, it can be considered as a reductive agent.

Stage 2 had showed a high value for $E_{p, a}$ and for $Q_{800}$, which agrees with the data obtained for HPLC quantification, when the sum of all metabolites showed high concentration values. Also, this stage exhibited high values for antioxidant capacity measurements (Fig. 2).

It must be noted that charge $\left(\mathrm{Q}_{800}\right)$ (Table 1$)$, total polyphenols and total metabolite quantification by HPCL have the same behavior, because charge is directly related to the electroactive species concentration. The oxidation potential peak values show a trend to decrease as a function of the maturation process, which implies an increase in the extract reduction power. The antioxidant capacity measured by DPPH assay shows the same trend, proving that this electrochemical measure has a high relation with the chemical probes traditionally used for the characterization of this kind of samples.

In order to propose electrochemical measurements as an alternative for the fruit extracts characterization, it was calculated a relation between the oxidation potential for each ripening stage, and Trolox oxidation potentials (reference patron). This relation, called $\mathrm{E}$ factor, indicates that when an extract has higher antioxidant capacities than Trolox, the relation is bigger than 1; otherwise, the relation is smaller than 1, as in Equation 1:

$$
E-\text { factor }=\frac{\text { First oxidation peak potential for the extract }}{\text { Oxidation peak potential for Trolox }}
$$

For the extracts, E-factor trends to decrease as a function of the maturation processes. Having into account that Trolox is being used as reference, the values over 1 imply lower antioxidant capacities than the standard, and values below 1 imply that the antioxidant capacity of the extract is better than that from Trolox. Also, to get better data interpretation, a simple correlation between ripening stage, DPPH assay, oxidation peak potential, and $\mathrm{E}$ factor was carried out. Results are shown in Table 4. 
Table 4. Correlation values between ripening state, DPPH assay, oxidation peak potential, and $\mathrm{E}$ factor.

\begin{tabular}{|c|c|c|c|c|}
\hline & $\begin{array}{l}\text { Ripening } \\
\text { stage }\end{array}$ & $\begin{array}{l}\text { Antioxidant capacity } \\
\text { (mg trolox } ® / 100 \text { g DF) }\end{array}$ & $\begin{array}{c}\text { Oxidation } \\
\text { peak potential }(\mathrm{V})\end{array}$ & E-factor \\
\hline Ripening stage & & $\begin{array}{l}0.8216 \\
(0.0000)\end{array}$ & $\begin{array}{l}-0.9267 \\
(0.0000)\end{array}$ & $\begin{array}{l}0.9313 \\
(0.0000)\end{array}$ \\
\hline $\begin{array}{l}\text { Antioxidant capacity } \\
(\mathrm{mg} \text { trolox } ₫ / 100 \mathrm{~g} \text { DF })\end{array}$ & $\begin{array}{l}0.8216 \\
(0.0000)\end{array}$ & & $\begin{array}{l}0.7269 \\
(0.0006)\end{array}$ & $\begin{array}{l}0.7622 \\
(0.0002)\end{array}$ \\
\hline $\begin{array}{l}\text { Oxidation peak potential } \\
\text { (V) }\end{array}$ & $\begin{array}{l}-0.9267 \\
(0.0000)\end{array}$ & $\begin{array}{l}0.7269 \\
(0.0006)\end{array}$ & & \\
\hline$E$ factor & $\begin{array}{l}0.9313 \\
(0.0000)\end{array}$ & $\begin{array}{l}0.7622 \\
(0.0002)\end{array}$ & $\begin{array}{l}0.9921 \\
(0.0000)\end{array}$ & \\
\hline
\end{tabular}

$\mathrm{n}=18,(P$-value $)$

From the table, it is clear that the best correlations with the ripening state are for E- factor and oxidation peak. Also, there is an acceptable correlation between the antioxidant capacity measured by DPPH and electrochemical variables.

A logarithm relation for the correlation curve with a $\mathrm{R}^{2}$ of -0.909512 was obtained. The equation, which represents this relation, is shown below (equation 2)

$$
E \text { factor }=[4,58321-0,583216 \times \operatorname{Ln}(\text { Antioxidant activity })]^{-1}
$$

This equation shows an inverse logarithmic relationship between DPPH assay and E- factor, and it could be used as another characterization and quality parameter for the study of fruits' nutraceutical properties.

On the other hand, it is possible to propose a model in which both E-factor and Trolox antioxidant equivalent are related to the ripening stage. This model is represented for the next equation with a $\mathrm{R}^{2}$ of 0.98907 and a P-Value $<0.05$. This result indicates that E-factor could be used as a characterization parameter for the maturation processes of V. Meridionale Swats (Equation 3).

$$
\text { Ripen. stage }=(0,00509421 \times \text { Antiox. activity })+(5,83629 \times \text { Efactor })(3)
$$

This is in accordance to the voltammetric results obtained in terms of the charge, in which, for S2, a high value was obtained, probably because these species are predominant in the extract. This equation could help to obtain differences for maturation stages, parameter which is very important, and has economic implications, such as the stage selection when the fruit has to be recollected to be packed and shipped for exportation.

\section{Conclusions}

Fruits maturation stage is a complex process, which implies changes in several metabolites, causing notable differences in the fruits physico-chemical characteristics. In this work, cyclic voltammetry was used as an alternative analytical tool for monitoring this process, and according to obtained results, it was showed that the information produced by this technique can be correlated 
with several measurements usually carried out for the characterization of this kind of systems. In addition, cyclic voltammetry has the advantage of low cost and simplicity compared to the other techniques above mentioned. Different parameters such as charge, oxidation potential and E-factor were correlated with the antioxidant capacities measured by DPPH method, total polyphenolic content measured by FC method, and metabolites quantification by HPLC-MS. Results showed a good correlation between cyclic voltammetry parameters (E-factor, specifically) and the antioxidant capacities measured by DPPH.

\section{Acknowledgments}

The authors would like to thank the Committee for the Development of Research-CODI-University of Antioquia for the support in the CPT-1233 project. Also, they would like to thank the chemist Jorge Hoyos-Arbeláez, for his valorous contribution to this work. Blandón-Naranjo would like to thank the

Departamento Administrativo de Ciencia, Tecnología e Innovación COLCIENCIAS, for the doctoral scholarship.

\section{References}

1. Giongo L, Poncetta P, Loretti P, et al. Postharvest Biol Technol. 2013;76:34-39.

2. Papandreou Ma, Dimakopoulou A, Linardaki ZI, et al. Behav Brain Res. 2009;198:352-358.

3. Yang B, Kortesniemi M. Curr Opin Food Sci. 2015;2:36-42.

4. Lopera YE, Fantinelli J, González Arbeláez LF, et al. Evid Based Complemen Alterna Med. 2013;2013:516727.

5. Fogliano V, Verde V, Randazzo G, et al. J Agric Food Chem. 1999;47:1035-1040.

6. Bernal L, Melo L, Díaz C. Rev Fac Nal Agr Medellín. 2014;67:7209-7218.

7. Castro C, Olarte Y, Rache L, et al. Agron Colomb. 2012;230:196-203.

8. Garzón Ga, Narváez CE, Riedl KM, et al. Food Chem. 2010;122:980-986.

9. Hosu A, Cristea V-M, Cimpoiu C. Food Chem. 2014;150:113-8.

10. Castrejón ADR, Eichholz I, Rohn S, et al. Food Chem. 2008;109:564-572.

11. Floegel A, Kim D, Chung S, et al. J Food Compos Anal. 2011;24:10431048.

12. Della Pelle F, González MC, Sergi M, et al. Anal Chem. 2015;87:69056911.

13. Piljac-Žegarac J, Valek L, Stipčević T, et al. Food Chem. 121 (2010;121:820-825.

14. Miller NJ, Rice-Evans CA. Food Chem. 1997;60:331-337.

15. Milardović S, Iveković D, Grabarić BS. Bioelectrochemistry. 2006;68:17580.

16. Del Carlo M, Amine A, M. Haddam, et al. Electroanalysis. 2012;24:889896.

17. Della Pelle F, Di Battista R, Vázquez L, et al. Appl Mater Today. 
2017;9:29-36.

18. Lino FM, De Sá LZ, Torres IMS, et al. Electrochim Acta. 2014;128:25-31.

19. Rebelo MJ, Rego R, Ferreira M, et al. Food Chem. 2013;141:566-573.

20. Sousa WR, da Rocha C, Cardoso CL, et al. J Food Compos Anal. 2004;17:619-633.

21. Chiou A, Panagopoulou Ea, Gatzali F, et al. Food Chem. 2014;146:157-65.

22. Blainski A, Lopes GC, de Mello JCP. Molecules. 2013;18:6852-65.

23. Yang LJ, Tang C, Xiong HY, et al. Bioelectrochemistry. 2009;75:158-162.

24. Timbola AK, De Souza CD, Giacomelli C, et al. Braz J Chem Soc. 2006; 17:1-13.

25. Valek L, Stipc T, Only FE. Food Chem. 2010;121:820-825.

26. Rice-Evans CA, Miller NJ, Paganga G. Free Radic Biol Med. 1996;20:933956.

27. Sawyer DT, Sobkowiak A, Roberts JL. In: Electrochem Chem. $2^{\text {nd }}$ edition. New York: Wiley-Interscience; 1995.

28. Yang Y, Mu S. Electrochim Acta. 2013;109:663-670.

29. Pisoschi AM, Pop A, Serban AI, et al. Electrochim Acta. 2014;121:443460.

30. Montoya CG, David J, Arredondo H, et al. Ver Fac Nac Agronomía. 2012;65:6487-6495.

31. Dewick PM. Medicinal Natural Products. A Biosynthetic Approach. $2^{\text {nd }}$ edition. New York: John Wiley \& Sons Ltd; 2002.

32. Hong G, Wang J, Zhang Y, et al. Plant Physiol Biochem. 2014;78:49-52.

33. Rani A, Singh K, Ahuja PS, et al. Gene. 2012;495:205-210.

34. Brand-Williams W, Cuvelier ME, Berset C. LWT - Food Sci Technol. 1995;28:25-30.

35. Han R-M, Zhang J-P, Skibsted LH. Molecules. 2012;17:2140-2160. 